\title{
Influence of Oil and Water Holdup on Mixture Velocity in Horizontal Flows
}

\begin{abstract}
Usage of a traversing beam gamma densitometer measurement for the phase fractions distribution of a mixture of water and kerosene was achieved experimentally in a horizontal pipe tube. The phase fractions distribution was determined with the beam being traversed in three directions for example 0,45 and $90^{\circ}$ of the vertical line passing through the axis of the pipe tube. Measurement was made at two positions spaced into $2.54 \mathrm{~cm}$ internal diameter along the $9.7 \mathrm{~m}$ pipe length $(1.0 \mathrm{~m}$ and $7.72 \mathrm{~m}$ along the horizontal pipe tube) with two input water fractions of 0.4 and 0.6. The measurement was done in two-phase oil water experimental rig (TOWER) facility. This facility allows the two fluids to be fed to the test section before they separated throughout the coalescer and returned once again to the test line. The flow developed naturally from an initial stratified flow in which the oil and water were introduced separately at the top and the bottom of the test section, respectively. The flows were such that the liquids were fully inter-dispersed by the end of the test section. The phase fractions distribution was shown to be homogeneously mixed near to the outlet of the test section. The mean hold-up was found to depend on the mixture velocity.
\end{abstract}

Keyword: Gamma Densitometer System, Horizontal Pipe, Holdup, Mixture Velocity 